\title{
PLANNING STRUCTURE OF TRADITIONAL SETTLEMENTS IN MOUNTAINOUS REGIONS IN GUIZHOU PROVINCE OF CHINA
}

\author{
Xu Wei', Svetozar Zavarikhin ${ }^{2}$ \\ 1,2 Saint Petersburg State University of Architecture and Civil Engineering, \\ Vtoraja Krasnoarmejskaja ul. 4, St. Petersburg, 190005, Russia \\ ${ }^{1}$ xuweiba@163.com, 22z-svetozar@mail.ru
}

\section{Abstract}

The paper considers types of planning structures of mountain settlements in South China. A typology of mountain landscape fragments has been developed; dependence of planning and settlement types on landscape types has been identified. The main types of settlement planning structures have been defined as follows: shrub, ribbon-like, linear, branching, and grouped. Public areas of settlements have been characterized.

Key words: mountain settlements, mountain terrain, planning

\section{Introduction}

Historical-architectural and landscape-spatial specificity of rural settlements are the real pivot of the history of the Chinese nation, clearly demonstrating the stability of ideals, diligence and wisdom of the people. Traditional living and working environment of old settlements still retain imperishable cultural charm and the form-creative energy. Especially transparently and expressively influence of natural context on architectural and design characteristics of living and working environment is presented in mountain settlements, particularly in settlements of Guizhou province, architectural and design specificities of which are still an only little studied phenomenon. By the way the physical preservation of these settlements is on the verge of extinction concerning present building activity, influence of globalization and capital outflow from regions to center. Therefore in recent years the government started generation of programs aimed at development of tourism and controlling of urban development in the areas of traditional living and working environment. All mentioned circumstances give particular relevance to research dedicated to architectural and spatial specificity of traditional settlements in the mountainous regions of China.

Specific (but although selective) studying of architecture of settlements in Guizhou province begun in 1940s.
The most known research of that period is that of Dai Yisuan concerning the architecture of traditional dwelling in Guangxi, Guizhou and Yunnan provinces. However, later because of economic crisis the studying of traditional living and working environment was limited to its elements only (towers, bridges, "tree huts" etc.). The contribution was made by Deng Yan, Hu Guanghua (2007), Luo Deqi (1983), Li Xiankui, Shi Ruoping, Shi Tingzang.

In 1990s in China started the period of analytical generalization of collected empiric material about traditional settlements including that of Guizhou province. Significant contribution was made by Tang Guoan, Peng Liguo, Wu ZhengGuang, Zhou Hongcan, Wang Qizun, Si Xinzhi, Li Xiankui, Jin Yu, Luo Deqi, Li Yuxiang, Guan Yanbo (1997), etc.

In XXI century studying of such aspects of traditional architecture as "environment and landscape", "preserving, reconstruction and development of traditional living and working environment were continued. This issues were discussed in works of Li Zhiying, Cheng Yan, Cai Lin, Wang Yuan, Gu Jin, Sun Wei (2005), Zhang Yilung, Yu Yafang, Long Yujie, Li Cenglai, ZhaoXing, LiuSenlin, WuZhengguan, Xiaomei Wang, Le Leceyun.

However, until now only individual aspects of traditional architecture of Guizhou province such as architec- 
ture of towers, crypts and temples have been studied in detail. Never before traditional settlements of the region have been treated as architectural-spatial compositions depending on natural context. Planning structures of such settlements (including their dependence on landscape) never were a subject of special and consistent study.

\section{Objectives}

Considering what was said above, the main objective of this article is to reveal the dependence of architectural and design characteristics of living and working environment on landscape and topography. In order to achieve this main objective there were stated specific task: to identify mountainous landscape types, which are suitable for settlement development, and corresponding types of settlements.

\section{Subject matter}

This paper is focused on the manner and lines of influence of landscape and climate factors on architectural and design specificity of living and working environment in mountainous regions of Guizhou province of China

\section{Methods}

The following methods have been used:

Comprehensive and interrelate studying of literary and cartographic materials and data of observations made in situ by author;

Problem-logical method of material analysis aimed at identification of typological dependence of planning structures of traditional living and working environment on the landscape.

\section{Main part}

The high-mountain regions of modern Guizhou province situated in the South-West of China were settled in as far back as the neolithic age (archeologists found more than two hundred of cave sites in the territory). Ancient settlements mostly were located along river banks and across mountain flat lands. About five thousand years ago, agricultural tribal communities which were not Chinese culture-bearers started to appear there. Active residential occupation by representatives of Han (Chinese) ethnic nationality began in the reign period of the Ming (1368-1644) dynasty. Therefore, formation of the system of Chinese settlements neighboring settlements of national minorities started in this mountain region.

Common topographic peculiarities of South China mountain regions are presence of slopes exposed to all directions and significant elevation changes (the difference between the lowest and the highest points in the Western part of the region is $2 \mathrm{~km}$ ) (Alekseev et al., 1991). The landscape type is influenced by karst and ice formations, almost three thousands of rivers with tributaries, and such relatively large main rivers as the Duliujiang, Qingshui, and Wuyanghe which are almost parallel to each other and flow from the West to the East following the common topographic feature. There, in the Eastern part of the re- gion, forests have always been growing due to the high humidity (Rapoport, 1987).

The region's landscape, geographic, and climatic peculiarities determined the locality of migration flows in course of the region occupation, and its relative isolation from the historical development of China. Therefore, conditions for long time presence of national cultures were created, including their architectural and city-planning aspects which, again, were directly dependent on the type of definite landscapes (Akira Fujii, 2003).

The diversity of natural conditions resulted in the diversity of settlement planning structures. The following factors affected settlement area selection: general slope, type of surrounding mountain slopes, presence of rivers, prevailing wind direction, availability of ploughable land, possibility of spatial development, exposition of the "background" slope (usually houses adjoined the northern slope to take full advantage of sun warmth and light). Settlements did not appear on the banks of swift-flowing rivers or in the places where a river could easily owerflow its banks. The area selection was also influenced by the sea-level altitude. Usually, the higher the settlement's level was, the less were the density and area of the development.

The classical type of the mountain settlement is the one located in the area with homogeneous terrain, e.g. on the mountain slope, its bottom or top. Depending on location, all region's settlements are divided into riverside, slope, and top settlements, settlements in gorges, and settlements on combined terrain. The research has showed that the settlements on mountain slopes make more than $40 \%$ of all region's settlements, $22 \%$ of settlements are located in river valleys, $14 \%$ are located at foothills, $8 \%$ are located on tops, and $14 \%$ are located on combined terrain (Wang Dehua, 2012).

Riverside settlements are the most popular ones. In this case, a particular site was selected near a mountain ridge, providing the required protection from cold winds. Therefore, such settlements usually stretched in a ribbon along a river and mountain ridge, sometimes forming a chain of several dozens of villages. Most often only one bank was reclaimed, however sometimes both banks were developed.

In cases when a settlement was located in a river bend, not only the narrow riverside was developed but remote areas as well. Another landscape was observed on both banks of a tributary river outflow (in mountainous regions, a river often has many closely located tributaries). In this case settlements were formed not linearly but compactly.

Settlements in gorges were formed on ploughable lands attractive for population dependent on agriculture. Therefore, these were the places of the earliest markets.

Slope settlements often appeared at high levels from the mountain foot. Mainly Miao and Yao people lived there (Xia Fei, 2009). Below slope settlements ploughable lands were usually located and a river flowed. Several settlements in that group appeared due to the rainy seasons. Other ones were located on natural terraces which offer the settlements an opportunity of continuous growth. 


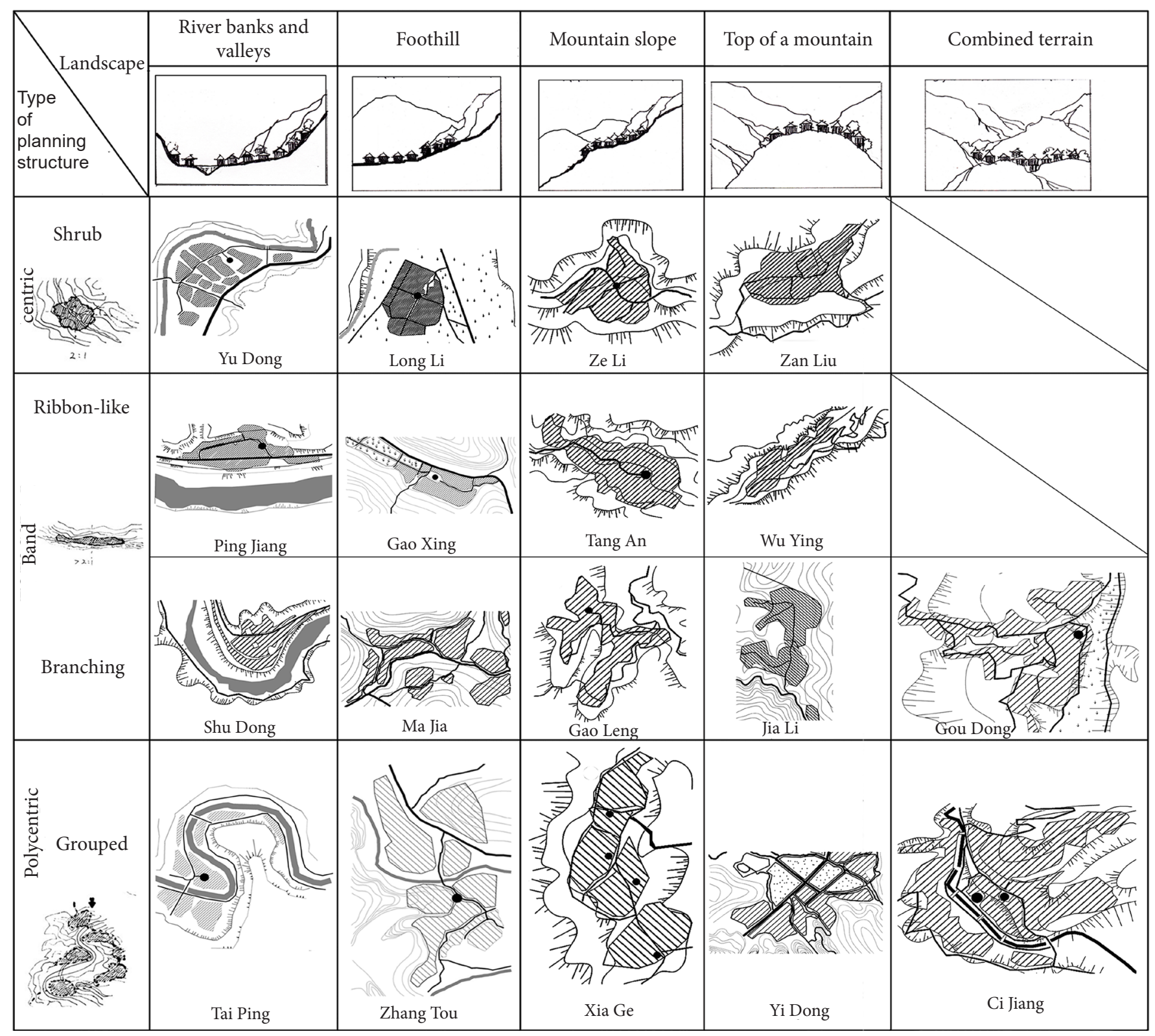

Fig. 1

Top settlements were located at mountains edges or on plateaus if those were relatively even. Such settlements were out of danger as to stone falls and avalanching, and had advantages for fortification (Novikov, Pustotsvetov, 1988). Besides, tops are usually rich in vegetation and fertile soil. A disadvantage of this location is the limited number of plots fit for development, as well as permanent shortage of water.

Settlements on combined terrain are formed in course of development gradually extending not only to the riverside but also to slopes and even mountains' tops. It happens upon combination of several factors, i.e. accessibility for transport, availability of ploughable lands, a river, and gentle slopes. Proximity to other settlements providing a chance of production cooperation also made its impact.

At first sight, the space organization in mountain settlements may seem chaotic; however, it has its logic since it accumulates the centuries-long experience of life in severe environment. The diversity of settlement planning structures may be reduced to five main types: shrub, ribbon-like, linear, branching, and grouped.

Shrub settlements are the most ancient ones, they usually occurred on mountains' tops. In the early period, the housing construction scale in that region was relatively small: developments were thrift and environmental impact was minimal. Initially the length to width ratio of the building footprint did not exceed 2:1 (Yuan Zhongjin, 2007) which allowed settlement expanding in all directions. Plans of almost all shrub structures are compact and close to round, oval, square or multangular form.

Shrub structures of various settlements were not identical to each other but they were formed on the basis of the area type. In high-mountain regions, settlements were small and were located generally on mountain tops or terraces. Buildings were densely located in clusters. Settlements on slopes suffered the minimum impact of the area terrain in course of their development; however, they also 
were close to each other. In course of settlements' expansion, their structure sometimes acquired a ribbon-like form.

Shrub settlements located in valleys and along river banks, in general, appeared on even plots between mountains. A river usually flowed either through a settlement or nearby. Depending on the size of even plots, settlements' sizes and functional potential varied from purely agricultural to trade. Such settlements often grew into midsized trade cities with more organized planning structure.

Ribbon-like settlements initially were compact shrub settlements, however, in course of development in corresponding landscapes they stretched along rivers, roads, or valleys. A ribbon-like structure or its varieties gradually formed (dotted, band or stellate structures). Ribbon-like settlements rarely appeared on edges of the mountain ridges and were rather small. Settlements on hills were midsize. However, due to such factors as significant area of even plots, fertile soil, availability of water resources, and proximity to transport routes, settlements in river basins got the advantage in development; therefore, their size was approximately twice as large as the average size of the settlements mentioned above (Pen Yi Gan, 1994). Ribbon-like settlements on steep slopes originally appeared as groups of houses near important transport routes.

The ribbon-like structure of settlements forms the corresponding path and road network with one or two axial mains going through the settlement. Transit mains outside settlements usually had the width of 5-8 m; inner paths and roads were moderate in width.

Linear settlements develop along a direct or polygonal line. As ribbon-like settlements, they may form long "dotted" lines. Generally, they are located on mountains' slopes and in river basins, on highlands or (rarely) in upper mountain belts. Most often such settlements stretch along a mountain ridge or terraces. The corresponding development factors are slope steepness and availability of transport link. Settlement form usually repeats the outlines of a ridge along which it is developing but the general structure preserves the linear form. Such settlements are mostly trade ones. An individual typological group is formed by parallel linear settlements. In any case, the linear structure predetermines appearance of two or more public centers and formation of a path and road network with one axial road which is either deadend or transit one.

Branching settlements appeared in branched valleys, on gorge bottoms or mountain ridges. Areas with a challenging terrain are considered as the least favorable for them, while the most favorable one is the mid of a mountain (Hou Tianjiang, 2006). Branched structures developed from linear or ray structures by way of branching from nodal points. Two kinds of such settlements may be distinguished: 1) with clear presence of the main branch and 2) with several equivalent branches. The branched structure was often formed around the main road leading to the mountain top and along main road branches on areas of various levels. Certainly, roads and paths were made with utmost rational use of particular terrain pecu- liarities. Therefore, roads could stretch lower or higher of individual houses.

Grouped settlements appeared in course of growth and merging of individual settlements. Therefore, they are large in size. Particular planning of settlements depends on their location. Unlike clustered structures, houses are located here at a significant distance from each other, offering more possibilities to adapt for the peculiarities of a definite plot. Planning aspects of such settlements are represented by two types, i.e. chain and stellate. The first type is formed by joint of various shrub or ribbon-like settlements interconnected with one or two roads. The second type is common for river valleys, bank terraces, and slopes. This type is the most popular.

Public areas of settlements are midsized areas with drum towers, stages, and other structures required for communication, ceremonials, etc. Public areas "break" the dense structure of settlement's plan, serve as guide marks, lend variety to the homogenuous street space, evoke a feeling of unity and safety. The number of public areas depends on the size of settlements and peculiarities of their planning structures. Even if a public center is located at the outskirts of a settlement, its location does not affect its significance as a center of this settlement (Ji Fuzhen, 2008).

Public centers may be closed, semi-closed, and open. Closed centers have midsized square developed along its perimeter with adjoining structures and residential houses. The access to the area is available only along a narrow street. In slope settlements, it is often necessary to go upwards to the level of $15 \mathrm{~m}$. In other cases, the center may be limited from three sides with a drum tower, well, stage, residential buildings and mountain slope. The closed space of the center may have several levels.

Public centers of open type do not have the closed perimeter; buildings and structures are located freely enough. In most cases such centers are located at the outskirts of settlements where open space is larger. In these cases a drum tower and stage located opposite each other often represent spatial dominants. The center structure may also contain an altar, chapel, gallery, well or water body (Sogomonyan, 1991). All elements forming the center reflect the relevant aspects of people's daily life. It is possible to highlight three types of organization of these elements such as ordered, open, and natural (corresponding to the terrain).

The ordered structure of the center falls in line with visually perceived axes or their clear turns. In the second case the overall visual picture is characterized by significant variety. Orderliness of the volumetric and spatial structure of the center may be intensified by building of two drum towers (in compliance with the tribal life organization in a settlement).

Public centers with an open structure are formed around multilevel squares with diverse mountain and a settlement views.

Natural structures of public centers most often can be met in settlements located on river banks, foothills or high in the mountains, since in these conditions development 
forcedly depends on the capability to consider natural terrain peculiarities.

Household buildings, spring wells, pavilions, bridges, big trees, etc. may serve as structural elements for public areas of settlements.

\section{Conclusion}

Complexity of mountain terrain stipulated limitation of migration flows in the region, which contributed to formation and preservation of the distinctive national culture and architecure. Settlements appeared and developed naturally in typical mountain landscape areas.

Original and new elements in this article consist not only of the method of graph-analytical comparison of typological models of landscape with models of planning structures of settlements, but also it consist of the subject matter itself, which never have become the object of specific scientific study.

The main findings are:

- in dependence of location mountain settlement in GuiZhou province are divided into riverside, slope, top, bottom, terrace settlements.

- the location of the settlement made impact on its planning structure, diversity of which may be reduced to five main types: shrub, ribbon-like, linear, branching, and grouped.

- the most important component of almost all settlements is a public center of closed, semi-closed or open type. Each of them may have the planning structure of open, ordered or natural (corresponding to the landscape) type.

\section{References}

Akira Fujii (2003) Rural Settlement of Visit. Ling translation. Architecture \& Building Press, Beijing, China.

Alekseev Al, Kovalev SA, Tkachenko AA. (1991) Geografiya sfery obsluzhivaniya: osnovnye ponyatiya i metody [Service sector geography: basic notions and methods]. Tver State Univerity, Tver, RF (in Russian).

Guan Yngbo (1997) Analytical background and functions of settlements of ethnic groups of southwestern China. National Studies journal, 6: 29-32 (in Chinese).

Hou Tianjiang (2006) Miao village in China - Xi Jiang. Ethnic Guizhou publishing house, Guiyang, China (in Chinese)

Hu Guanghua, Yang Zuhua (2007) Guizhou. The ancient village of Zhaoxing. Guizhou Ethnic Publishing House, Guiyang, China (in Chinese).

Ji Fuzhen (2008) A new look at vernacular architecture. Huangshan bookstore

Luo Deci (1983) Architecture, stone, people. Journal of architecture, 11: 76-86 (in Chinese)

Novikov VA, Pustotsvetov GI (1988) Arkhitekturnaya organizatsiya sel'skoi sredy. Uchebnoe posobie [Architectural organization of rural environment. Teaching guide]. Novosibirsk State Academy of Architecture and Arts, Novosibirsk, RF (in Russian).

Pen Yi Gan (1994) The traditional rural settlement landscape analysis. China Building Industry Press, Beijing, China (in Chinese)

Rapoport A (1987) House Form and Culture.

Sogomonyan NM (1991) Sel'skii zhiloi dom (proektirovanie, zastroika usad'by) [Farmhouse (design, building development)]. Agropromizdat, Moscow, RF (in Russian).

Sun Wei (2005). Ecological view. Research, development and characterization of a traditional urban settlement in the mountainous areas in the southeast of Guizhou. Master of Architecture and Civil Engineering Thesis (085213), Si Chuan, China (in Chinese).

Wang Dehua (2012) Chinese landscape culture and city planning. South-East University publishing house, Nanjing, China (in Chinese).

Xia Fei (2009). Analysis of the bank line landscape in traditional rural settlements of Dong people. Master of Folk Arts thesis (030405), KunmMing, China (in Chinese).

Yuan Zhongjin (2007) Development strategy of Chinese populated areas. South-East University publishing house, Nanjing, China (in Chinese). 